\title{
Comparable expression of matrix metalloproteinases 1 and 2 in pouchitis and ulcerative colitis
}

\author{
A Stallmach, C C Chan, K-W Ecker, G Feifel, H Herbst, D Schuppan, M Zeitz
}

Department of Internal Medicine II, Saarland University, Saar, Germany

A Stallmach

C C Chan

M Zeitz

Department of Internal Medicine, Cathay General Hospital, Taipei, Taiwan

C C Chan

Department of Surgery, Saarland University, Saar, Germany

K-W Ecker

G Feifel

Gerhard-DomagkDepartment of

Pathology, University of Münster, Germany H Herbst

Department of Internal Medicine I, Friedrich-Alexander University

Erlangen-Nuremberg, Nuremberg, Germany

D Schuppan

Correspondence to: Dr A Stallmach, Clinic for Internal Medicine II,

Saarland University, 66421

Homburg/Saar, Germany

Email:

inasta@med-rz.uni-sb.de

Accepted for publication 7 March 2000

\begin{abstract}
Background and aims-Matrix metalloproteinases (MMPs) are implicated in the tissue destruction associated with inflammatory diseases. Proctocolectomy with ileo-anal pouch (IAP) anastomosis is associated with pouchitis, particularly in patients with ulcerative colitis (UC). The aim of this study was to quantify MMP-1 and $M M P-2$ in inflamed and uninflamed pouches of patients with UC compared with those with active UC. IAP patients with familial adenomatous polyposis (FAP) served as controls.

Methods-Biopsies were taken from 33 patients with IAP (UC, $n=25 ; F A P, n=8)$ and from 10 UC patients. MMP-1 and MMP-2 were quantified using sandwich enzyme linked immunosorbent assays. In addition, northern and western blotting and in situ hybridisation experiments were performed.

Results-In pouchitis $(\mathrm{n}=11), \mathrm{MMP}-1$ and MMP-2 concentrations were increased compared with uninflamed pouches of patients with UC $(n=14)$ or FAP $(n=8)$ (MMP-1 $17.7 \mathrm{ng} / \mathrm{mg}$ protein $v 7.8$ (UC) $v$ 7.6 (FAP), p $\leqslant 0.05$; MMP-2 $16.4 v 9.5$ (UC) $v 6.3$ (FAP), $\mathrm{p} \leqslant 0.05)$. Western and northern blots revealed increased MMP-1 and MMP-2 protein and transcript concentrations in inflamed pouches. Mesenchymal cells were identified as major producers of MMP-1 and MMP-2 in pouchitis. A similar increase in MMPs was observed in tissues of patients with active UC.

Conclusions-Our results support the hypothesis that MMPs are involved in mucosal destruction and crypt hyperplasia, as seen in pouchitis.

(Gut 2000;47:415-422)
\end{abstract}

Keywords: ileo-anal pouch; matrix metalloproteinases; pouchitis

Total proctocolectomy followed by formation of an ileo-anal pouch (IAP) is a well established surgical procedure for patients with chronic ulcerative colitis (UC) or familial adenomatous polyposis (FAP). ${ }^{12}$ Pouchitis is a well known complication following restorative proctocolectomy and is most common in UC patients with a reported incidence of $7-42 \% .^{3}$ Inflammation of the pouch (pouchitis) is reflected by macroscopic lesions such as erythema, haemorrhage, focal ulcerations, aphthous lesions, and severe crypt hyperplasia.
Recent observations suggest that the extracellular matrix (ECM) actively controls the key steps in the process of wound healing and tissue regeneration (for review see Raghow ${ }^{4}$ ). Increased synthesis and functional activity of matrix degrading enzymes was related to tissue injury in a number of disease states. ${ }^{5-8}$ Degradation of the ECM during both normal tissue remodelling and in pathological conditions is achieved through the concerted action of a diverse array of extracellular proteases. Among these, the matrix metalloproteinases (MMPs) are of central importance. At present 24 different MMPs are known, not all of which are currently characterised for their biological function. ${ }^{9}$ They are divided into three subclasses based on substrate specificity ${ }^{10}$ and are produced by various cell types (that is, fibroblasts and inflammatory cells). There are multiple levels at which expression and activation of MMPs and their physiological counterparts, the tissue inhibitors of metalloproteinases (TIMPs), are regulated, and biologically active agents such as growth factors, cytokines, and oncogenes are inducers of gene expression. MMP-1 (synonymous with interstitial collagenase or collagenase type I) is the main enzyme that cleaves fibrillar collagen, namely types I, II, III, VII, and X. Cleavage of intact fibrillar collagens is in fact restricted to MMP-1 and MMP-5 (interstitial and neutrophil collagenases). MMP-2 (synonymous with collagenase type IV or gelatinase A) degrades type IV (basement membrane), type V, and type VII collagens, as well as denaturated collagens, and plays a crucial role in collagen degradation of connective tissue. ${ }^{11} 12 \mathrm{MMP}-3$ (synonymous with stromelysin 1) can enhance the activity of MMP-1 and degrades a wide range of ECM components. MMP-3 is of central importance in normal tissue remodelling ${ }^{13}$ and causes severe tissue injury when added directly to explant cultures of fetal human intestine. ${ }^{14}$ We and others have shown in previous studies that levels of MMP-1, MMP-2, and MMP-3 mRNA are increased in UC. ${ }^{15-17}$ Using zymography, which is the standard technique for measuring the functional activity of proteases, Baugh and coworkers demonstrated an increase in metalloproteinase activity in inflamed mucosa in patients with UC and

Abbreviations used in this paper: IAP, ileo-anal pouch; MMPs, matrix metalloproteinases; UC, ulcerative colitis; FAP, familial adenomatous polyposis; ECM, extracellular matrix; TIMPs, tissue inhibitors of metalloproteinases; PDAI, pouchitis disease activity index; IL, interleukin; TNF- $\alpha$, tumour necrosis factor $\alpha$. 
Crohn's disease. ${ }^{18}$ Of the proteases detected, MMP-9 was the most abundantly expressed in the inflamed bowel. Further studies implicating MMPs in intestinal tissue destruction came from Saarialho-Kere et al who demonstrated an increase in MMPs in human gastrointestinal ulcers. ${ }^{19}{ }^{20}$

As pouchitis is accompanied by focal ulcerations, villous atrophy, and crypt hyperplasia, in our first set of experiments we quantified mucosal concentrations of MMP-1 and MMP-2 in IAP to test the hypothesis that these enzymes have a role in the pathogenesis of pouchitis. Our data showed that expression of MMP-1 and MMP-2 protein was increased in acute pouchitis and was associated with crypt hyperplasia as a morphological correlate of intestinal remodelling.

\section{Material and methods \\ PATIENTS}

From January 1996 until January 1999, 33 patients with IAPs were investigated. The first group represented 14 UC patients with a noninflamed IAP. In the second group $11 \mathrm{UC}$ patients with clinical, endoscopic, and histological signs of pouchitis were included. Activity of pouchitis was assessed using the pouchitis disease activity index (PDAI) described by Sandborn. ${ }^{3}$ Acute pouchitis was defined as an index greater than seven points. Follow up studies were performed in eight patients with acute pouchitis who were treated for two weeks with metronidazole (1200 mg orally/day). These patients served as an intraindividual comparison after improvement of pouchitis. Eight patients with FAP who had an IAP after proctocolectomy served as controls. All patients had a proctocolectomy with creation of an ileo-anal J pouch by a two stage or one stage procedure performed by the same team of surgeons. Mucosal biopsies were obtained during endoscopy from IAPs and the neoterminal adjacent ileum. All pouch biopsies were obtained within $5-10 \mathrm{~cm}$ of the anal verge using a flexible sigmoidoscope (Olympus, Heidelberg, Germany). Ileal biopsies were taken $10-15 \mathrm{~cm}$ proximal to the IAP. For ethical reasons it was not possible to take more than eight biopsies from each region. Therefore, in all patients two biopsies were used for conventional histological analysis and microdissection, and three biopsies for determination of MMP-1 and MMP-2 concentrations by ELISA (see below). The remaining biopsies were used for western or northern blotting or for in situ hybridisation. Ten patients with active UC (rectosigmoid region, median age 36 years (range 17-59)) served as a second control group. In these patients biopsies were taken from macroscopic/histological inflamed and uninflamed segments. Samples for ELISA, or western or northern blotting were immediately snap frozen in $0.9 \% \mathrm{NaCl}$ and stored at $-80^{\circ} \mathrm{C}$. For in situ hybridisation experiments, biopsies were fixed in $4 \%$ formalin.

DETECTION OF MMPS BY ELISA

Three biopsy specimens (10-20 mg) were thawed in protease inhibitor solution (Com- plete, Boehringer, Germany) and transferred to neutral buffer $(0.1 \mathrm{M} \mathrm{NaCl}, 0.01 \mathrm{M}$ Tris, $\mathrm{pH}$ 7.6, $0.001 \mathrm{M}$ EDTA) containing the proteinase inhibitors. Biopsies were homogenised mechanically followed by centrifugation at $4000 \mathrm{~g}$ for 10 minutes. Quantitation of MMPs in supernatants was performed using commercially available MMP-1 and MMP-2 ELISAs as described by the manufacturer (Amersham Buchler, Braunschweig, Germany). MMP assays recognise the precursors of $\mathrm{MMP}-1$ and MMP-2 (proMMPs) - that is, free proMMP-1 and proMMP-2 and MMP-1/-2 complexed with TIMP - but not active forms of MMPs. The limit of detection for MMP-1 was 1.7 $\mathrm{ng} / \mathrm{ml}$ and for MMP-2 $0.37 \mathrm{ng} / \mathrm{ml}$. MMP-1 and MMP-2 concentrations are expressed as $\mathrm{mg}$ of total protein, as measured in the samples using the BioRad assay (BioRad DC Protein Assay Kit, Bio-Rad, Munich, Germany).

To determine intra-assay variation, part of a proctocolectomy specimen was homogenised in $2 \mathrm{ml}$ of neutral buffer and MMP-1 and MMP-2 concentrations were determined in several fractions. The coefficient of variance was $9.1 \%$. In addition, to analyse variations in MMP-1 and MMP-2 concentrations in a defined inflamed segment of UC, multiple biopsies were taken from this segment. The variation per given area of MMP-1 and MMP-2 concentrations was $20.2-25.7 \mathrm{ng} / \mathrm{mg}$ protein and $21.2-33.2 \mathrm{ng} / \mathrm{mg}$ protein, respectively ( $n=6)$. To quantify MMP-1 and MMP-2 concentrations in normal tissue, samples of colonic mucosa were removed from macroscopically normal colon of patients with colorectal carcinomas $(n=20)$. In this group, median MMP-1 and MMP-2 concentrations were $7.7 \mathrm{ng} / \mathrm{mg}$ protein (range 2.2-20.4) and $4.75 \mathrm{ng} / \mathrm{mg}$ protein (range $1.7-13.2$ ), respectively.

\section{WESTERN BLOTTING}

For western blotting experiments, three biopsies from each patient were homogenised in detergent buffer (1.1 M urea, $2 \%$ sodium dodecyl sulphate, $0.01 \%$ bromphenol blue, $2 \%$ dithiothreitol). Subsequently, samples were heated for 15 minutes at $95^{\circ} \mathrm{C}$ followed by centrifugation at $4000 \mathrm{~g}$ for 10 minutes. Similar amounts of supernatant protein $(10 \mu \mathrm{g}$ per lane) were loaded in each lane of a $10 \%$ sodium dodecyl sulphate-polyacrylamide gel electrophoresis under reducing conditions. After gel electrophoresis, proteins were transferred to nitrocellulose membranes. Monoclonal antihuman MMP-1 or antihuman MMP-2 antibodies (Oncogene, Cambridge, Massachusetts, USA) were used at a dilution of 1:100. These antibodies recognise both the active and proenzyme forms of MMPs. A goat antimouse antibody conjugated to horseradish peroxidase (Dianova, Hamburg, Germany) was used as a secondary antibody (1:5000). Bands were visualised using diaminobenzidine as chromogenic substrate. Computer assisted scanning densitometry (Image Gauge 3.0, Fuji, Japan) was used to analyse the intensity of the immunoreactive bands in western blots. Where bands of proMMP and active forms of MMPs 
Table 1 Mucosal concentrations of MMPs (ng/mg protein) in inflamed and uninflamed pouches and in inflamed and uninflamed areas in patients with ulcerative colitis (UC)

\begin{tabular}{llllll}
\hline & & & & UC patients $(n=10)$ \\
\cline { 5 - 6 } & $\begin{array}{l}\text { UC patients with } \\
\text { pouchitis }(n=11)\end{array}$ & $\begin{array}{l}\text { UC patients without } \\
\text { pouchitis }(n=14)\end{array}$ & $\begin{array}{l}\text { FAP patient pouch } \\
\text { samples }(n=8)\end{array}$ & Inflamed mucosa & Normal mucosa \\
\hline MMP-1 & $17.7(11.1-25.8)^{\star}$ & $7.8(4.9-13.1)$ & $7.6(6.3-9.1)$ & $12.7(9.9-47.1)^{\star}$ & $6.5(5.3-12.0)$ \\
MMP-2 & $16.4(12.2-23.4)^{\star}$ & $9.5(3.7-12.9)$ & $6.3(4.7-23.4)$ & $27.8(6.1-78.7)^{\star}$ & $8.3(4.2-12.1)$ \\
\hline
\end{tabular}

MMP concentrations were determined by ELISA as described in material and methods. Values are median (minimum and maximum values).

${ }^{\star} \mathrm{p} \leqslant 0.05$ compared with UC patients without pouchitis.

are presented, the optical densities of individual bands were added to measure total MMP-1 or MMP-2 in tissue.

PROBES

RNA probes were prepared by subcloning the $0.73 \mathrm{kB} E c o R \mathrm{I} /$ SstI (5' probe) and the $0.7 \mathrm{kB}$ Sst I/BglII (3' probe) fragments of plasmid $\mathrm{pX} 7$ (No 57684, American Type Culture collection, Rockville, Maryland, USA) inserting a human MMP-1 cDNA into the transcription vector pGEM1 (Promega Biotech, Madison, Wisconsin, USA) at the appropriate restriction sites. The 3' $B g l \mathrm{II} / E c o \mathrm{RI}(0.7 \mathrm{~kb})$ fragment of pK-121 harbouring a human MMP-2 cDNA (kindly provided by Dr Huhtala) was also subcloned into pGEM1. After linearisation of the plasmids with EcoRI, single stranded RNA probes, either complementary (antisense probe) or anticomplementary (sense probe, negative control) to cellular RNA transcripts were obtained using SP6 or T7 RNA polymerase (Gibc-BRL, Karlsruhe, Germany) by run off transcription. $\left[{ }^{35} \mathrm{~S}\right]$ labelled uridine
5- $\alpha$ [thio] triphosphate (NEN, Dupont, Dreieich, Germany) was used to generate in situ hybridisation probes with an average specific activity of $1.2-1.4 \times 10^{9} \mathrm{cpm} / \mu \mathrm{g}$.

NORTHERN BLOT ANALYSIS

RNA from three biopsies from each patient was isolated using a commercially available mRNA purification kit (Quickprep Micro mRNA Purification Kit, Pharmacia Biotech, Freiburg, Germany). Biopsies were lysed by homogenisation in $0.6 \mathrm{ml}$ of a buffer containing $4 \mathrm{M}$ guanidine thiocyanate, $50 \mathrm{mM}$ Tris (hydroxymethyl) aminomethane $\mathrm{HCl}, \mathrm{pH} 7.5,10 \mathrm{mM}$ EDTA, $0.5 \%$ sodium laurylsarcosine, and $0.1 \mathrm{M}$ mercaptoethanol. The homogenate was cleared by a short centrifugation, and the supernatant was transferred to a microcentrifuge tube containing oligo(dt)-cellulose. The tube was centrifuged for 10 seconds, and the supernatant removed from the pelleted oligo(dt)-cellulose. The pellet was then washed sequentially with high salt and low salt buffer. mRNA was eluted by means of a microcolumn,
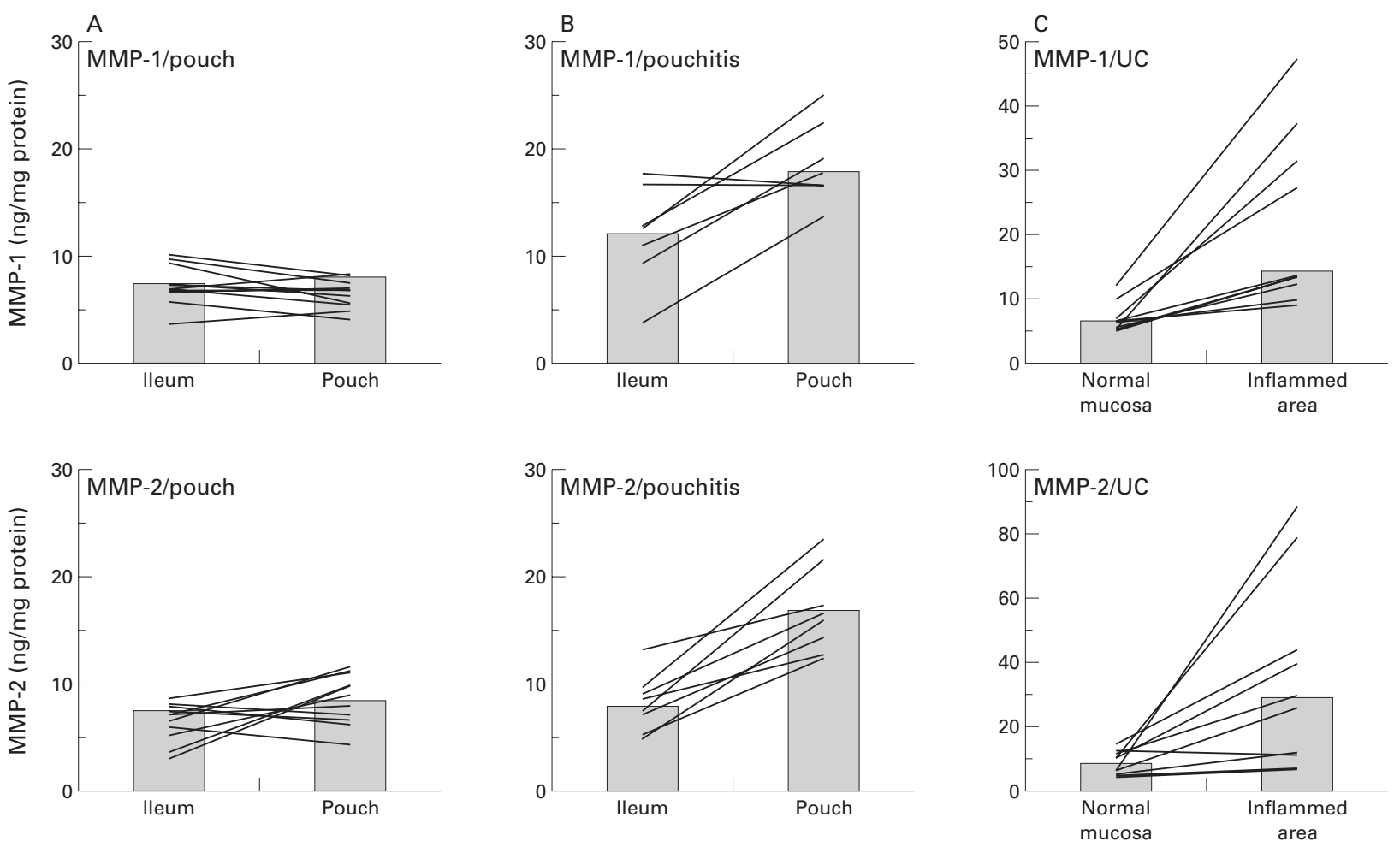

Figure 1 MMP-1 and MMP-2 concentrations in uninflamed pouches, in pouchitis, and in active ulcerative colitis (UC). Mucosal biopsies were taken from ileo-anal pouches and the adjacent ileum from individual patients without $(A)(n=10)$ or with pouchitis $(B)(n=7)$ and from patients with active UC $(C)(n=10)$. For technical reasons it was not possible to take ileal biopsies in one patient with pouchitis and four patients with uninflamed pouches. MMP-1 and MMP-2 concentrations were determined as described in material and methods. Columns represent the median of all patients; lines connect intraindividual MMP-1 and MMP-2 concentrations. 

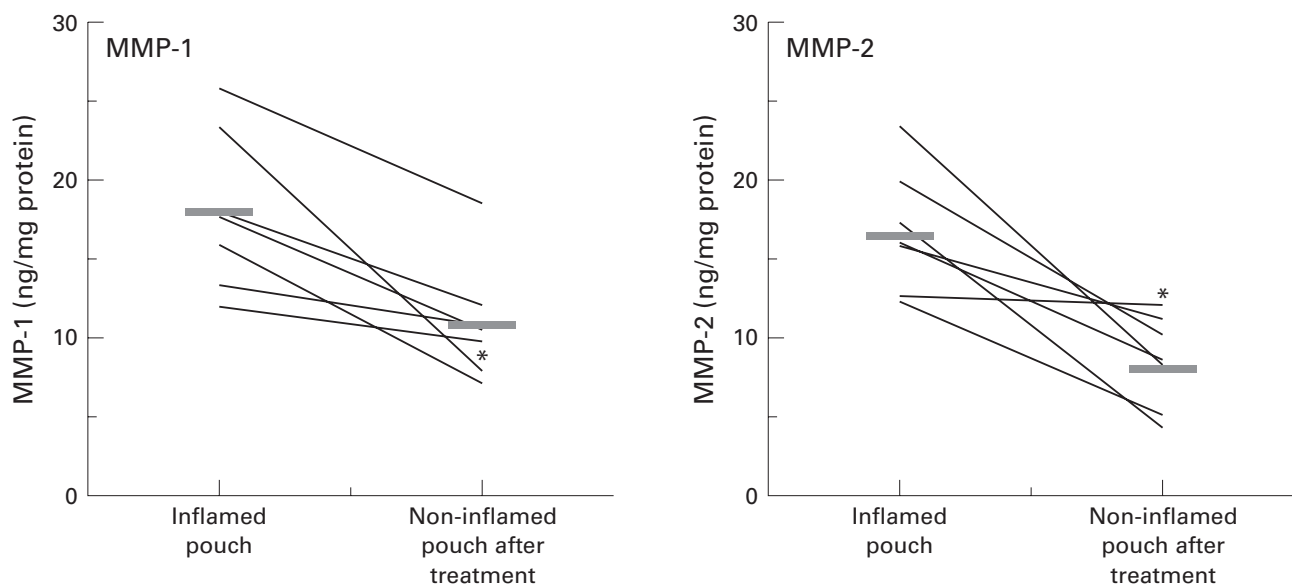

Figure 2 Concentrations of MMP-1 and MMP-2 after treatment of pouchitis. Mucosal biopsies were taken from ileo-anal pouches from individual patients $(n=7)$ with pouchitis before and after treatment with metronidazole for two weeks, and analysed for MMP-1 and MMP-2 concentrations. Lines connect the follow up values for MMP concentrations before and after normalisation of clinical and endoscopic signs of inflammation; bars represent median of all patients. In one patient $\left.{ }^{\star}\right)$, endoscopic follow up after treatment did not show a significant improvement in mucosal inflammation. However, clinical and histological parameters improved.

ethanol precipitated, and redissolved in distilled water. mRNA was denaturated, subjected to electrophoresis through $1 \%$ agarose in the presence of formaldehyde, and transferred to nitrocellulose, as described previously. ${ }^{21} \mathrm{Hy}-$ bridisation was carried out using MMP-1 and MMP-2 probes (see above). For generation of MMP-1 and MMP-2 specific probes, DNA was digoxigenin labelled by random primer extension. Filters were washed sequentially in $2 \times, 0.5 \times$, and $0.1 \times$ standard saline citrate in the presence of $0.1 \%$ sodium dodecyl sulphate at $68^{\circ} \mathrm{C}$ for 30 minutes. To ensure that equal amounts of RNA were loaded, filters were incubated with an MMP-2 specific probe and a digoxigenin labelled $\beta$-actin sample (Boehringer, Mannheim, Germany) which is characterised by a typical $1.7 \mathrm{kB}$ band in parallel. As MMP-1 and $\beta$-actin RNA are located in the same region, mRNA was divided into two samples and processed in parallel. Finally, an antidigoxigenin-alkaline phosphatase antibody (1:5000) (Boehringer) was added. After additional washing steps $(2 \times 15$ minutes $)$ the staining solution containing the colour substrates nitroblue tetrazolium chloride and 5-bromo-4chloro-3-indolyl phosphate, toluidine salt, was added and development of the blue colour was observed. mRNA bands were quantified by densitometry as described above.

IN SITU HYBRIDISATION EXPERIMENTS

In addition to northern blots we used in situ hybridisation to characterise MMP transcript expression in pouchitis and identify MMP-1 and MMP-2 RNA expressing cells. RNA expression of MMP-1 and MMP-2 was examined on paraffin embedded tissue sections with ${ }^{35} \mathrm{~S}$ labelled MMP-1 and MMP-2 specific riboprobes (see above). Prehybridisation, hybridisation, washing procedures, including removal of non-specifically bound probes by ribonuclease A digestion, and autoradiography of slides were performed as described in detail previously. ${ }^{22-24}$ As a negative control sense probes to MMP-1 and MMP-2 were used.
STATISTICAL ANALYSIS

Results are given as median (range). Statistical significance was calculated using the Wilcoxon rank test, and was considered significant at $\mathrm{p} \leqslant 0.05$. Spearman rank correlation coefficients were calculated using the StatView $\mathrm{SE}^{+}$ Graphics program on a Macintosh computer.

\section{Results}

DETECTION OF MMP-1 AND MMP-2 IN MUCOSAL BIOPSIES

Using an ELISA technique, mucosal concentrations of MMP-1 and MMP-2 in IAPs were determined in patients with and without pouchitis. In UC patients with pouchitis $(n=11)$, tissue concentrations of MMP-1 and MMP-2 were increased compared with UC patients $(n=14)$ and FAP patients $(n=8)$ without pouchitis (table 1). Furthermore, in individual patients, concentrations of both MMPs in inflamed pouches were significantly increased compared with non-inflamed ileal mucosa (fig 1). Increased MMP-1 and MMP-2 concentrations in pouchitis were comparable with MMP concentrations in active UC. In inflamed segments, both metalloproteinases (MMP-1 and MMP-2) were significantly increased compared with uninflamed segments in the same patient (see table 1, fig 1). Concentrations of MMP-1 and MMP-2 in uninflamed colon of patients with UC were similar to mucosal concentrations in normal mucosa of patients with colorectal carcinomas (see material and methods).

TREATMENT OF POUCHITIS RESULTED IN A DECREASE IN MMP-1 AND MMP-2

CONCENTRATIONS

As concentrations of MMPs were increased in pouchitis, we investigated the effect of medical treatment (metronidazole) on MMP-1 and MMP-2 concentrations in patients with acute pouchitis. After a median follow up of six weeks, a significant decrease in both MMPs in seven of eight patients was observed after improvement of clinical symptoms and 


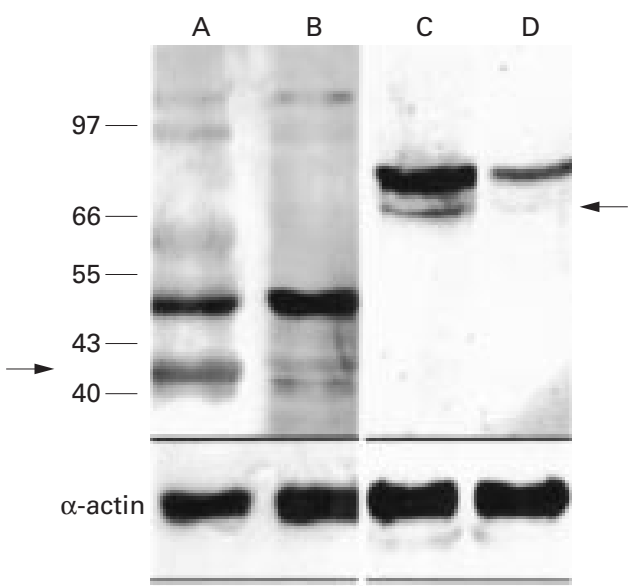

Figure 3 Western blot analysis of $M M P-1$ and $M M P-2$ expression. Western blotting revealed increased concentrations of MMP proenzymes in pouchitis. Lanes $A$ and $C$, pouchitis; lanes $B$ and $D$, uninflamed pouch. Lanes $A$ and $B, M M P-1$; lanes $C$ and $D, M M P-2$ (arrows indicate the $42 \mathrm{kDa} M M P-1$ and the $66 \mathrm{kDa} M M P-2)$. The lower part of the figure shows results of western blot analysis using an a-actin specific antibody to demonstrate equal protein load on each lane.

endoscopic/histological signs of pouchitis (fig 2). In one patient with pouchitis, PDAI decreased from 8 to 6 points. Endoscopic examination of the pouch revealed persistent erosions and ulcers. In this patient MMP-1 concentrations decreased from 25.8 to 7.7 $\mathrm{ng} / \mathrm{mg}$ protein. However, no significant decrease in MMP-2 concentration was observed $(12.0 \mathrm{ng} / \mathrm{mg}$ protein before treatment and 11.7 $\mathrm{ng} / \mathrm{mg}$ protein after treatment) (see fig 2 ).

PRESENCE OF PROTEOLYTICALLY ACTIVATED MMPs IN POUCHITIS

To analyse the ratio of MMP proenzymes and proteolytically activated enzymes, tissue extracts were subjected to western blotting and normalised by comparison with smooth muscle $\alpha$-actin (fig 3). Densitometric evaluation of the $M M P-1 / \alpha$-actin ratio and $M M P-2 / \alpha$-actin ratio, as detected by western blots in samples from patients with pouchitis $(n=5)$ and patients without pouchitis $(n=5)$, demonstrated an increase in MMP-1 or MMP-2 in pouchitis compared with uninflamed pouches (table 2). More importantly, only in biopsies from patients with pouchitis were two bands of $52 \mathrm{kDa}$ and $42 \mathrm{kDa}$ or $72 \mathrm{kDa}$ and $66 \mathrm{kDa}$ found which were compatible with detection of zymogen and the proteolytically activated MMP-1 and MMP-2, respectively (fig 3). Taken together, these findings confirm the quantitative differences in MMPs between inflamed and non-inflamed pouches and indi-

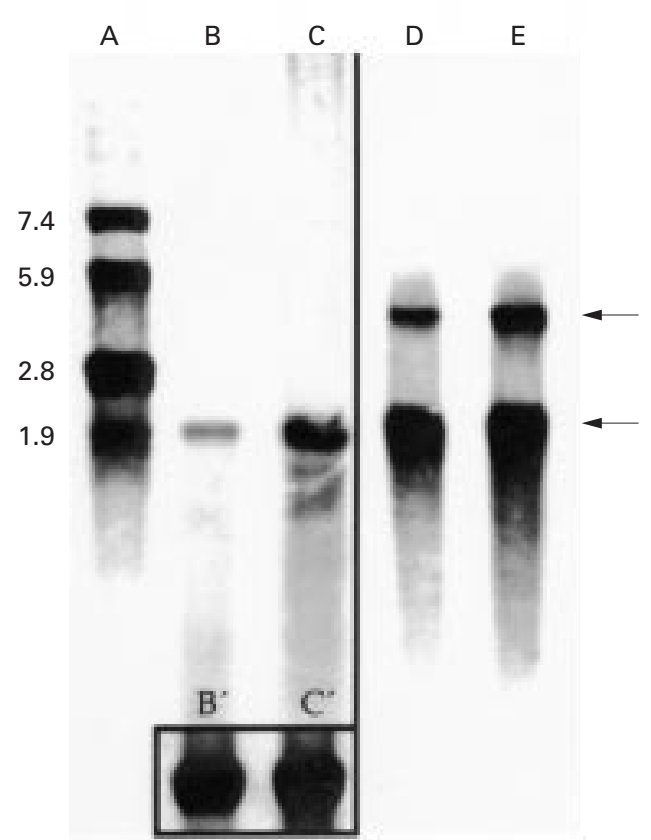

Figure 4 Northern blot analysis of $M M P-1$ - and $M M P-2$ in mucosal biopsies from patients with pouchitis. Northern blot analysis of $M M P-1$ (lanes $B, C$ ) and $M M P-2$ (lanes $D$ and $E$, upper arrow $3.1 \mathrm{kB}$ ) and $\beta$-actin $R N A$ (lower arrow $1.7 \mathrm{kB}$ ). The box in the lower part of lanes $B$ and $C$ represents $\beta$-actin $R N A$ of $B$ and $C$. Lane $A$ represents the RNA bp standard. $m R N A$ was extracted from biopsies from the adjacent uninflamed ileum serving as an internal control (lanes $B$ and D) and inflamed pouch (lanes $C$ and $E$ ). A representative example of one of five patients is shown.

cate that the presence of activated enzymes is related to pouch inflammation.

INCREASED MMP-1 AND -2 TRANSCRIPTS IN POUCHITIS

To confirm the ELISA and western blotting data, northern blot analyses were performed with mRNA extracts from patients without pouchitis $(n=6)$ and from patients with inflamed pouches $(n=4)$. Figure 4 shows a northern blot analysis from an inflamed pouch and an uninflamed ileum using MMP-1 and MMP-2 specific probes. In the uninflamed ileum or uninflamed pouch only a weak band corresponding to MMP-1 mRNA was seen (see fig 4, lane B) whereas a stronger signal was found in biopsies from pouchitis (fig 4, lane C). A similar pattern of signal intensities was observed when northern blots were probed for MMP-2 mRNA (fig 4, lanes D, E). Densitometric evaluation of MMP mRNA bands, as detected by northern blots, revealed an increased ratio of MMP-1 and MMP-2 transcript concentrations in samples from patients

Table 2 Densitometric evaluation of MMP/actin as detected by western blots in samples from patients with and without pouchitis

\begin{tabular}{lllll}
\hline & MMP-1/actin & $\begin{array}{l}\text { Active form of } \\
\text { MMP-1/actin }\end{array}$ & MMP-2/actin & $\begin{array}{l}\text { Active form of } \\
\text { MMP-2/actin }\end{array}$ \\
\hline Pouchitis (n=5) & $\begin{array}{l}77.67 \%(26.5-138.8) \\
\text { Uninflamed pouch (n=5) }\end{array}$ & $\begin{array}{l}30.9 \%(12.1-60.5) \\
12.3 \%(1.944 .8)^{\star}\end{array}$ & $\begin{array}{l}69.6 \%(32.6-115.9) \\
23.4 \%(18.0-37.5)^{\star}\end{array}$ & $\begin{array}{c}16.9 \%(10.1-25.3) \\
4.7 \%(2.5-6.8)^{\star}\end{array}$ \\
\hline
\end{tabular}

Intensity of bands in western blots were quantified as described in material and methods.

Concentrations of MMPs are expressed as percentages in relation to optical actin bands (minimum and maximum values are indicated in parentheses).

${ }^{\star} \mathrm{p} \leqslant 0.05$. 

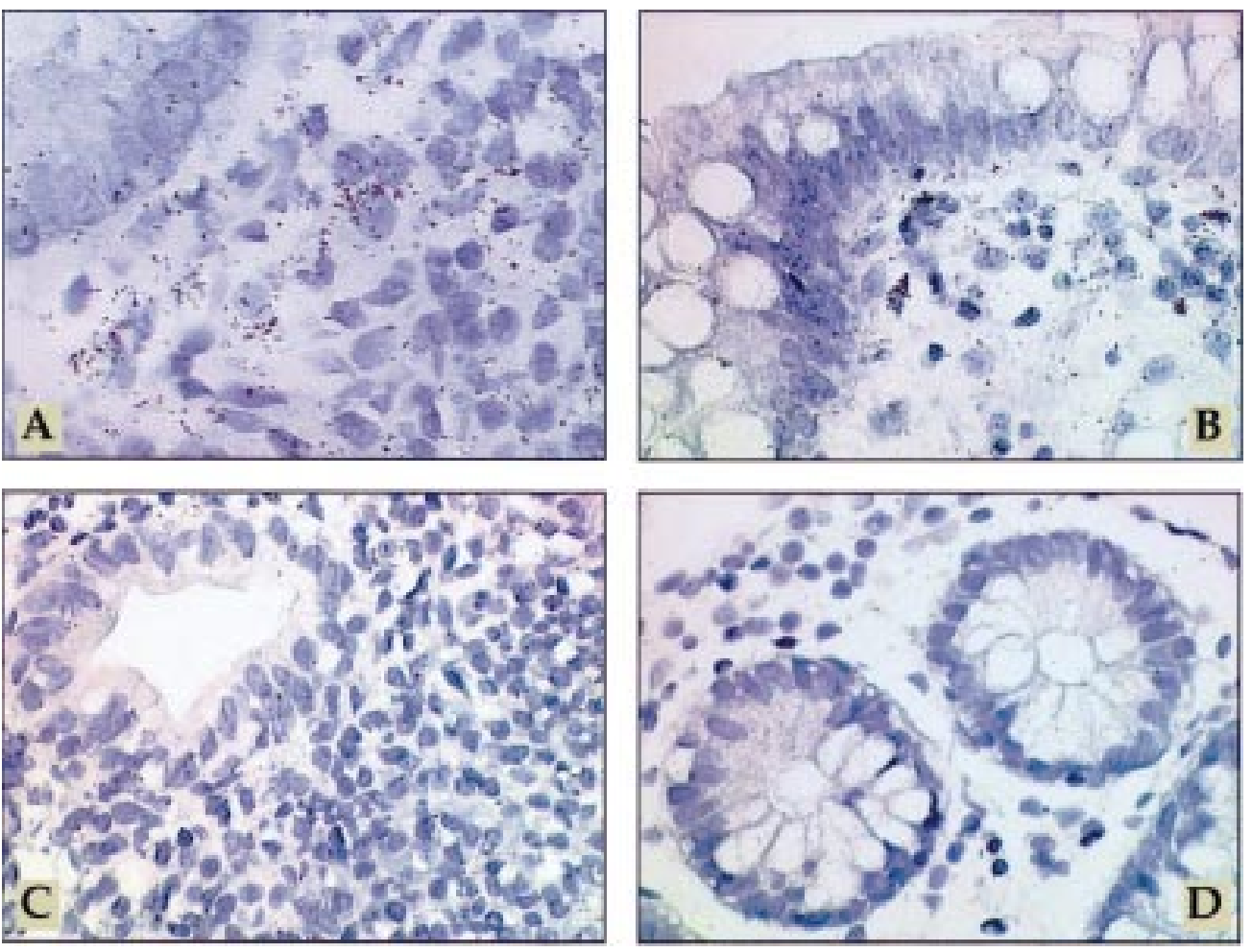

Figure 5 Mesenchymal cells are major producers of $M M P-1$ and $M M P-2$ in pouchitis. In situ hybridisation with [ $\left.{ }^{5} S\right]$ labelled MMP-1 antisense RNA probe $(A)$ or $\left[{ }^{35} S\right]$ labelled $M M P-2$ antisense $R N A$ probe (B) in pouchitis. In inflamed pouches a large number of strongly labelled cells is visible in the lamina propria, mainly directly underneath the epithelium $(A, B) .\left[^{35} S\right]$ labelled MMP-1 sense RNA probe $(C)$ in pouchitis, demonstrating the background signal. In situ hybridisation with $\left.{ }^{35} S\right]$ labelled $M M P-2$ antisense RNA probe (D) on ileum tissue with mild inflammation. In the uninflamed ileum grains are localised over mesenchymal cells of the lamina propria, predominantly underneath the epithelium. However, transcript levels were near the threshold of detection in most cases. Exposure time in all sections was 28 days. Original magnification $\times 600$.

with pouchitis (MMP-1/ $\beta$-actin mRNA ratio 0.43 (median) (min $0.27 ; \max 0.49) ; \mathrm{MMP}-2 /$ $\beta$-actin mRNA ratio $0.5(0.23-0.55))$ compared with transcript concentrations in patients without pouchitis (MMP- $1 / \beta$-actin $\mathrm{mRNA}$ ratio 0.11 ( $\min 0.07, \max 0.18), \mathrm{MMP}-2 /$ $\beta$-actin mRNA ratio $0.16(0.08-0.18))$.

In addition to northern blots we performed in situ hybridisation to characterise MMP transcript expression in pouchitis and identify MMP-1 and MMP-2 RNA expressing cells. In pouchitis $(n=2), M M P-1$ and MMP-2 gene transcript levels were markedly increased in cells of the lamina propria, especially in spindle shaped cells of the lamina propria, predominantly in the cell layer located directly underneath the epithelial cell layer (subepithelial myofibroblast sheet) (fig 5A, B). The number of labelled cells was higher than in the adjacent ileum and correlated with the cellular density of the inflammatory infiltrate. Intraindividual comparison revealed low MMP-1 and MMP-2 gene transcript steady state levels in specimens of ileum that showed only weak or moderate signs of chronic and unspecific inflammation (fig 5D). In parallel, in uninflamed pouches $(n=2), M M P-1$ and MMP-2 transcript levels were near the threshold of detection in most cases, requiring extended exposure times. In summary, the intensity of the autoradiographic MMP-1 and MMP-2transcript specific signals was positively correlated with the cellular density of the inflamma- tory infiltrate and significantly increased in inflamed pouches.

\section{Discussion}

Current concepts of the pathogenesis of pouchitis postulate that inflammation in patients with IAP after proctocolectomy may represent recurrence of UC in the small intestinal mucosa under different conditions. We and others have described increased concentrations of MMP transcripts, including MMP-1 and MMP-2 mRNA in UC. ${ }^{10}{ }^{16}$ To determine if MMP concentrations change and lead to degradation of the ECM in pouchitis, in a first set of experiments we quantified MMP-1 and MMP-2 in biopsies of IAPs from patients with and without pouchitis and compared the values with MMP concentrations in active colitis. We showed significant increases in concentrations of MMP-1 and MMP-2 in both pouchitis and active colitis compared with mucosal specimens from uninflamed pouches, normal ileal mucosa, or uninvolved colon. We complemented our study by using western and northern blot analysis, demonstrating increased MMP-1 and MMP-2 mRNA and protein content in pouchitis compared with uninflamed pouches or uninflamed ileum from the same patients. Recently published data from von Lampe et al support our data. Using competitive RT-PCR, they demonstrated increased MMP-1 and MMP-2 transcripts in pouchitis compared with uninflamed pouches. ${ }^{25}$ How- 
ever, it is possible that the increase in mucosal MMP-1 and MMP-2 concentrations in pouchitis compared with non-inflamed pouch mucosa could be an underestimation of the in vivo situation which may be characterised by increased activation of MMPs in relation to proenzyme concentrations. Detection of active forms of both enzymes (MMP-1 and MMP-2) using western blot analysis in tissue extracts from our patients with pouchitis compared with uninflamed pouches supports this hypothesis.

Production of MMPs by inflammatory cells has recently received increased attention. In agreement with the results of Pender's group, who described mesenchymal cells as major producers of MMPs in explants of fetal gut, ${ }^{26}$ we identified, using in situ hybridisation, spindle shaped cells of the lamina propria, predominantly in the cell layer located directly underneath the epithelial cell layer as the major source of MMPs in pouchitis. In addition, Milani et al described vimentin positive, CD68 negative mesenchymal cells as producers of MMPs in normal and fibrotic human liver. ${ }^{27}$ However, as immunohistological staining of MMP positive cells in pouchitis was not performed, we cannot exclude the fact that polymorphonuclear leucocytes also produce MMPs, especially MMP-2, as described by Bailey and coworkers. ${ }^{15}$

$\mathrm{T}$ cells and macrophages that are resident next to mesenchymal cells may play a regulatory role in MMP production. In pouchitis, local concentrations of proinflammatory cytokines such as interleukin 1 (IL-1) and interferon $\gamma$ are markedly increased. ${ }^{28}{ }^{29}$ Cell culture studies revealed that IL- $1 \beta$ caused an increase in steady state levels of $\mathrm{MMP}-1$ mRNA in a human intestinal smooth muscle cell line. ${ }^{30}$ Recently it was shown that IL-1 $\beta$ activates $\mathrm{AP}-1$ and protein kinase $\mathrm{C}$ dependent signal transduction pathways in human skin fibroblasts or intestinal smooth muscle cells. ${ }^{31}{ }^{33}$ However, the direct effect of IL-1 $\beta$ on intestinal fibroblasts isolated from patients with IAPs is unknown. Additional inflammatory mediators, such as tumour necrosis factor $\alpha$ (TNF- $\alpha)$, are also potent physiological stimuli for metalloproteinase production in mesenchymal cells. ${ }^{144}$ We have also shown that treatment with metronidazole normalises MMP-1 and MMP-2 levels in active pouchitis. Based on the findings that MMPs are not increased in biopsies from normal pouch mucosa and that proinflammatory cytokines such as IL- $1 \beta$ or TNF- $\alpha$ are potent inducers of MMPs, we would predict that any therapy that reduces mucosal inflammation will lead to reduction in MMP concentrations. Indeed, we have previously shown in acute pouchitis that metronidazole downregulates the state of activation of mucosal lymphocytes. ${ }^{28}$ Recent attention has focused on monoclonal anti$\mathrm{TNF}-\alpha$ antibodies as an efficient treatment for destructive and fistulising Crohn's disease. ${ }^{35}$ Blockade of TNF- $\alpha$ has dramatic effects on the ability of the matrix to restore itself. Treatment with anti-TNF- $\alpha$ antibodies caused downregulation of MMP-1 and MMP-3 in the serum of patients with active rheumatoid arthritis. ${ }^{36}$ In addition, in an in vivo model of $\mathrm{T}$ cell mediated matrix degradation in explants of human fetal intestine, blockade of TNF- $\alpha$ prevented matrix degradation. ${ }^{37}$

In one patient with persistent endoscopic signs of pouchitis, treatment with metronidazole resulted in a decrease in MMP-1 but not MMP-2 concentrations (see fig 2). It should be noted that a patchy distribution of inflammation was found in $64 \%$ of pouchitis patients. ${ }^{38}$ Therefore, it is possible that MMPs are elevated in inflamed areas (patchy lesions) and normal in adjacent uninflamed areas. However, in our study the increase in mucosal MMP concentrations in pouchitis was generally paralleled by the presence of focal ulcerations, aphthous lesions, and crypt hyperplasia. These are only indirect lines of evidence supporting a destructive role for MMPs in vivo. However, data from in vitro studies revealed a causal relation between MMP concentration and mucosal destruction. Addition of recombinant MMPs caused mucosal destruction in fetal small intestinal explants with villous atrophy, crypt hyperplasia, and shedding of epithelial cell. ${ }^{14}$ These authors also showed that addition of inhibitors of MMPs resulted in inhibition of tissue injury. Villous atrophy and crypt hyperplasia are also characteristic features of active coeliac disease. Using the in situ hybridisation technique, Daum and coworkers detected an increase in MMP-1 mRNA steady state concentrations in areas of villous atrophy and crypt hyperplasia in untreated coeliac disease. ${ }^{39}$ Taken together, these data indicate a strong relationship between MMPs and mucosal transformation. However, net ECM degrading proteolytic activity results from the balance between local concentrations of activated enzymes and their endogenous inhibitors. Therefore, analysis of TIMP-1 and TIMP-2 concentrations in acute pouchitis is of special interest. In this context it is important to note that MMP-3 is markedly overexpressed in inflamed intestinal mucosa of patients with inflammatory bowel disease whereas TIMP-1 remains unaltered (T T MacDonald, personal communication).

In conclusion, our data provide evidence that increased levels of intestinal MMP-1 and MMP-2 play a major role in degradation of the intestinal matrix and are probably the final step in the cascade of events leading to tissue injury in pouchitis.

This work was supported by grants from the German Crohn's disease and Ulcerative Colitis Association (DCCV e V) and the Deutsche Forschungsgemeinschaft (DFG Sta 295/4-1, DFG Ze 188/7-1). AS is the recipient of a Heisenberg professorship of the DFG (Sta 295/3-1). The authors thank the nursing staff of the endos (Sta 2 the endoscopy department for their help in specimen collection and $\mathrm{H}$ Baus-Kettl for technical assistance. We thank B Romeike (Department of Neuropathology, Saarland University) for documentation of in situ hybridisation micrographs and $\mathrm{P}$
Huhtala for the gift of a cDNA probe.

\footnotetext{
1 Parks AG, Nicholls RJ. Proctocolectomy without ileostomy. BMF 1978;2:85-8.

2 Taylor BA, Dozois RR. The J ileal pouch-anal anastomosis. World f Surg 1987;11:727-34.

3 Sandborn WJ. Pouchitis following ileal pouch-anal anastomosis: definition, pathogenesis, and treatment. Gastroenterology 1994;107:1856-60.
} 
4 Raghow R. The role of extracellular matrix in postinflammatory wound healing and fibrosis. FASEB 7 1994;8:823 31.

5 Airola K, Vaalamo M, Reunala T, Saarialho KU. Enhanced expression of interstitial collagenase, stromelysin-1, and urokinase plasminogen activator in lesions of dermatitis herpetiformis. F Invest Dermatol 1995;105:184-9.

6 Clark IM, Powell LK, Ramsey S, Hazleman BL, Cawston TE. The measurement of collagenase, tissue inhibitor of metalloproteinases (TIMP), and collagenase-TIMP complex in synovial fluids from patients with osteoarthritis and rheumatoid arthritis. Arthritis Rheum 1993;36:372-9.

7 Conway JG, Wakefield JA, Brown RH, et al. Inhibition of cartilage and bone destruction in adjuvant arthritis in the rat by a matrix metalloproteinase inhibitor. 7 Exp Med 1995;182:449-57.

8 Gunja SZ, Morales AR, Romanelli R, Woessner JJ. Remodeling of human myocardial collagen in idiopathic dilated cardiomyopathy. Role of metalloproteinases and pyridinocardiomyopathy. Role of metalloproteinases and

9 Grant G, Gimbernardi T, Grant A, Klebe R. Overview of expression of matrix metalloproteinases (MMP-17, MMP18 , and MMP-20) in cultured human cells. Matrix Bio 1999;18:145-8.

10 Matrisian L. The matrix-degrading metalloproteinases. Bioessays 1992;14:455-63

11 Woessner JFJ. Matrix metalloproteinases and their inhibitors in connective tissue remodeling. FASEB $f$ 1991;5: 2145-54.

12 Kerkvliet EH, Docherty AJ, Beertsen W, Everts V. Collagen breakdown in soft connective tissue explants is associated with the level of gelatinase A (MMMP-2) but not with collagenase. Matrix Biol 1999;18:373-80.

13 Sympson CJ, Talhouk RS, Alexander CM, et al. Targeted expression of stromelysin-1 in mammary gland provides evidence for a role of proteinases in branching morphogenexis and the require proteinases in branching for tissue-specific gene expression. f Cell Biol 1994;125: 681-93.

14 Pender SL, Tickle SP, Docherty AJP, Howie D, Wathen NC, MacDonald TT. A major role for matrix metalloprotein-
ases in T cell injury in the gut. F Immunol 1997;158:158290.

15 Bailey CJ, Hembry RM, Alexander A, Irving MH, Grant $\mathrm{ME}$, Shuttleworth CA. Distribution of the matrix metalloproteinases stromelysin, gelatinases $\mathrm{A}$ and $\mathrm{B}$, and collagenase in Crohn's disease and normal intestine. F Clin Pathol 1994;47:113-16.

16 Matthes H, Matthes B, Stallmach A, Schuppan D, Herbst $\mathrm{H}$, Riecken EO. mRNA expression of collagenase type I and IV is increased in ulcerative colitis compared to Crohn's

17 Günther U, Matthes H, Herbst H, Stallmach A, Riecken EO, Schuppan D. Phenotype of cells expressing matrix metalloproteinases-3 in ulcerative colitis. Ann N Y Acad Sci 1998;859:304-6.

18 Baugh MD, Perry MJ, Hollander AP, et al. Matrix metalloproteinase levels are elevated in inflammatory bowel proteinase levels are elevated in infla

19 Saarialho-Kere U, Vaalamo M, Puolakkainen P, Airola K, Parks W, Karjalainen-Lindsberg $M$. Enhanced expression of matrilysin, collagenase, and stromelysin-1 in gastrointestinal ulcers. Am F Pathol 1996;148:519-26.

20 Vaalamo M, Karjalainen-Lindsberg ML, Puolakkainen P, Kere J, Saarialho-Kere U. Distinct expression profiles of stromelysin-2 (MMP-10), collagenase-3 (MMP-13), macrophage metalloelastase (MMP-12), and tissue inhibitor of metalloproteinases-3 (TIMP-3) in intestinal ulcerations. Am f Pathol 1998;152:1005-14.
21 Maniatis T, Fritsch EF, Sambrook J. Molecular cloning: a laboratory manual. New York: Cold Spring Harbor Laboratory Press, 1982.

22 Matthes H, Herbst H, Schuppan D, et al. Cellular localization of procollagen gene transcripts in inflammatory bowel diseases. Gastroenterology 1992;102:431-42.

23 Orzechowski H-D, Beckenbach C, Herbst H, Stölzel U, Riecken EO, Stallmach A. Expression of CD44v6 is associated with cellular dysplasia in colorectal epithelial cells. Eur f Cancer 1995;31A:2073-9.

24 Günther U, Schuppan D, Bauer M, et al. Fibrogenesis and fibrolysis in collagenous colitis: Patterns of procollagen types I and IV, matrix-metalloproteinase-1 and -13 , and TIMP-1-gene expression. Am f Pathol 1999;155:493-503.

25 von Lampe B, Barthel B, Kroesen AJ, Buhr HJ, Riecken EO, Rosewicz S. Zentrale Role der Matrix-Metalloproteinase-1 und ihres Inhibitors bei der mukosalen Adaptation im ileoanalen Pouch sowie bei der Pouchitis. Z Gastroenterol 1999;37:857A.

26 Pender SLF, Breese EJ, Günther U, et al. Suppression of T cell-mediated injury in human gut by interleukin 10: role of matrix metalloproteinases. Gastroenterology 1998;115:57383.

27 Milani S, Herbst H, Schuppan D, et al. Differential expression of matrix-metalloproteinase- 1 and -2 genes in normal and fibrotic human liver. Am f Pathol 1994;144:528-37.

28 Stallmach A, Schäfer F, Weber S, et al. Increased state of activation of CD4-positive T cells and elevated interferon- $\gamma$ production in pouchitis. Gut 1998;43:499-505.

29 Patel RT, Bain I, Youngs D, Keighley MRB. Cytokine production in pouchitis is similar to that in ulcerative colitis. Dis Colon Rectum 1995;38:831-7.

30 Graham MF, Willey A, Adams J, Yager D, Diegelmann RF. Interleukin 1 beta down-regulates collagen and augments collagenase expression in human intestinal smooth muscle cells. Gastroenterology 1996;110:344-50.

31 Unemori EN, Bair MJ, Bauer EA, Amento EP. Stromelysin expression regulates collagenase activation in human fibroblasts. Dissociable control of two metalloproteinases by interferon-gamma. F Biol Chem 1991;266:23477-82.

32 Krane SM. Some molecular mechanisms of glucocorticoid action. Brf Rheumatol 1993;32(suppl 2):3-5.

33 Graham MF, Willey A, Zhu YN, Sugerman H. Critical interaction of c-jun and glucocorticoid receptor in the regulation of collagenase-1 expression by human intestin smooth muscle cells. Gastroenterology 1999;116:A726.

34 Brenner DA, O'Hara M, Angel P, Chojkier M, Karin M. Prolonged activation of jun and collagenase genes by tumour necrosis factor-alpha. Nature 1989;337:661-3.

35 Present DH, Rutgeerts P, Targan S, et al. Infliximab for the treatment of fistulas in patients

36 Brennan FM, Browne KA, Green PA, Jaspar JM, Maini RN, Feldmann M. Reduction of serum matrix metalloproteinase 1 and matrix metalloproteinase 3 in rheumatoid arthritis patients following anti-tumour necrosis factor-alpha (cA2) therapy. Br ₹ Rheumatol 1997;36:643-50.

37 Pender SL, Fell JM, Chamow SM, Ashkenazi A, MacDonald TT. A p 55 TNF receptor immunoadhesin prevents T cell-mediated intestinal injury by inhibiting matrix metalloproteinase production. F Immunol 1998;160:4098-103.

38 Shepherd NA, Jass JR, Duval I, Moskowitz RL, Nicholls RJ, Morson BC. Restorative proctocolectomy with ileal Morson BC. Restorative proctocolectomy with ileal biopsy specimens. F Clin Pathol 1987;40:601-7.

39 Daum S, Bauer U, Foss HD, et al. Expression of mRNA for matrix metalloproteinases 1 and 3 , tissue inhibitor of metalloproteinases-1 and collagen-1 in intestinal biopsies of patients with coeliac disease. Gut 1999;44:17-24. 